\title{
Flicker Suppression Scheme for Variable-Speed Wind Turbine Systems
}

\author{
Tan Luong Van*, Thanh Hai Nguyen", and Dong-Choon Lee ${ }^{\dagger}$ \\ ${ }^{\dagger *}$ Dept. of Electrical Engineering, Yeungnam University, Gyeongsan, Korea
}

\begin{abstract}
This paper proposes a strategy of flicker mitigation for doubly-fed induction generator (DFIG) wind turbine systems. In the weak grid system where the grid impedance ratio is low, the reactive power compensation only cannot suppress the flicker sufficiently due to the limited power capacity of the converters or the DFIG. For the full suppression of flickers, the active power smoothening using the energy storage system (ESS) needs to be utilized together with the reactive power compensation. The effectiveness of the proposed method is verified by PSCAD/EMTDC simulation results for a 2[MW] DFIG wind turbine system and by experimental results for a $3[\mathrm{~kW}]$ wind turbine simulator.
\end{abstract}

Key Words: Doubly-fed induction generator, Energy storage system, Flicker mitigation, Power fluctuation, Variable-speed wind turbine

\section{INTRODUCTION}

The penetration of wind energy into the electrical power grid is being developed rapidly in recent years. As the penetration level is extensively increased, the influence of the wind turbines on the power quality becomes so significant. It is known that one of the important power quality issues is a flicker [1]. Flicker is defined as "an impression of luminance fluctuations, whose frequencies are approximate $0.005 \mathrm{~Hz}$ to $35 \mathrm{~Hz}$ " [2], which can cause consumer annoyance and complaint. Furthermore, the flicker is considered as a serious issue and may restrict the integration of the wind turbine into the grid.

The flicker emitted from the grid-connected wind turbines is mainly caused by fluctuations in the output power. In the variable-speed wind turbine systems, the output power is much fluctuated due to the wind speed variations [3], [4]. Also, the output power contains the fluctuating frequency components such as 3p, 6p, 9p, etc. that are caused by the wind shear and tower shadow effects [5]. In addition, the changes of the grid conditions such as short-circuit ratio, type of loads, and grid impedance angle affect the flicker emission [3], [4], [6].

Manuscript received Oct. 24, 2011; revised Feb. 20, 2012

Recommended for publication by Associate Editor Seung-Ho Song.

${ }^{\dagger}$ Corresponding Author: dclee@yu.ac.kr

Tel: +82-53-810-2582, Fax: +82-53-810-4767, Yeungnam University

*Dept. of Electrical Engineering, Yeungnam University, Gyeongsan, Korea
Normally, the variable-speed wind turbines produce a lower flicker emission than the fixed-speed types due to the power smoothening effect by the flywheel of rotor. However, the flicker study is essential as the level of wind power penetration increases quickly.

Several solutions have been suggested to reduce the flicker from the grid-connected wind turbines. In one category, the reactive power at the PCC is controlled so that the power factor angle lags the grid impedance angle by 90 degrees. By this reactive power compensation, the voltage drop between the grid and the PCC becomes zero and then the flicker can be suppressed. The required reactive power can be provided by the grid-side converter (GSC) [7], [8], or the rotor-side converter (RSC) [9], or the static synchronous compensator (STATCOM) installed at the PCC [10]. In some cases where the grid impedance ratio is low, the reactive power compensation for flicker suppression is insufficient due to the limited power capacity of the converters or the DFIG [11], [12]. For this, a technique of the active power curtailment has been proposed, which can reduce the voltage variation at the PCC [11]. In this method, however, the active power of wind turbines transferred to the grid is decreased.

Also, the flicker mitigation controller has been proposed to dampen the 3p active power fluctuation of wind turbines by varying the DC-link voltage of the full-scale converters for the PMSG wind power systems [13]. Even with this control, however, the wind speed variations, the wind shear and tower 
shadow effects still produce the flicker with higher frequency components such as $6 \mathrm{p}, 9 \mathrm{p}, 12 \mathrm{p}$, etc.

In this paper, a new method combining the reactive power and active power control is proposed for the flicker mitigation. With this scheme, the active power fluctuations due to the wind shear and tower shadow effects can be fully suppressed for the DFIG wind turbine system, where the ESS at the DC-link of the converter is employed to absorb the power fluctuation. Also, the flicker caused by the wind speed variations, is compensated by the reactive power control at the RSC.

This paper is organized as follows. The simulation model of the variable-speed DFIG wind turbines is described in Section II. Next, the control schemes of the DFIG systems are described in Section III. Then, the strategy of reactive power compensation and the modeling of the energy storage system are described in Section IV and V, respectively. The flicker mitigation by the reactive power compensation and active power smoothening is presented in Section VI. In Section VII, the simulation results for a 2[MW] DFIG wind turbine system will be investigated. Finally, the experimental results for a $3[\mathrm{~kW}]$ DFIG wind turbine system are illustrated in Section VIII.

\section{MODEL OF WIND TURBINE SYSTEMS}

The modeling of wind turbine systems includes the aerodynamic characteristic of the blades, the transmission system and the electrical components such as the DFIG, back-to-back PWM converters, transformer, and the control system. The system configuration of a DFIG wind turbine connected to the grid is shown in Fig. 1.

\section{A. Wind speed modeling}

The variations of the wind speed can be represented as a sum of the harmonic components. Thus, the modeling of the wind speed is expressed in a function of time as [14]

$$
v_{w}(t)=V_{0}+\sum_{i=1}^{N} V_{i} \cos \left(\omega_{i} t+\varphi_{i}\right)
$$

where $V_{0}$ is the mean value of the wind speed, $N$ is the number of harmonic samples, $\omega_{i}$ is the harmonic frequency $\left(f_{i}=0.015 \sim 50 \mathrm{~Hz}\right), V_{i}$ is the amplitude of each harmonics, and $\varphi_{i}$ is a phase angle which is randomly produced in the domain $[-\pi, \pi]$.

\section{B. Blade modeling}

The aerodynamic model of a wind turbine is characterized by its $C_{p}(\lambda, \beta)$ curve, where $C_{p}$ represents the power conversion coefficient that is a function of the tip-speed-ratio $\lambda$ and the blade pitch angle $\beta$ [degrees] [15], [16].

The turbine torque that the wind turbine extracts from the wind is expressed as [13]

$$
T_{m}=0.5 \rho \pi R^{3} \frac{C_{p}(\lambda, \beta)}{\lambda} \cdot v_{w}^{2}
$$

where $\rho$ is the air density $\left[\mathrm{kg} / \mathrm{m}^{3}\right], R$ is the radius of the blade [m], $\omega$ is the wind turbine rotor speed $[\mathrm{rad} / \mathrm{s}], v_{w}$ is the wind velocity $[\mathrm{m} / \mathrm{s}]$, and $\lambda=\omega \cdot R / v_{w}$ is the tip-speed-ratio.

\section{Tower shadow and wind shear effects}

The tower shadow effect is caused by the resistance of the turbine tower to the wind flow and its disturbances to both upstream and downstream wind flows. The torque oscillations due to the tower shadow effect can be modeled as [17]

$$
T_{\text {shadow }}=-t_{\text {shadow }} \cdot \cos \psi
$$

for $-\psi_{\tau} \leq \psi \leq \psi_{\tau}$, where $\psi_{\tau}$ is a half of the angle of the sector under the influence of the tower, and $t_{\text {shadow }}$ is an empirical coefficient.

Due to the wind speed variation with the height, the torque oscillations produced by the wind shear can be expressed as

$$
T_{\text {shear }}=-t_{\text {shear }} \cdot \cos \psi
$$

where $t_{\text {shear }}$ is the empirical coefficient of the wind shear and $\psi$ is the rotating angle of the blades from the tower.

The resultant turbine torque, $T_{i}$, is expressed as

$$
T_{i}=T_{m}+T_{\text {shear }}+T_{\text {shadow }}
$$

For simulation, PSCAD/EMTDC software provides the models of the grid, the electrical components, the specific structure of wind turbines, the DFIG, the power converters, and other libraries [18]. For the model of back-to-back PWM converters, the power switching devices are usually used in the computer simulation, which requires a large size of memory and the long execution time. Since the flicker calculation requires a long simulation time (10 minutes for the short-term flicker), it is inconvenient to use the actual model of power switches for the flicker investigation in the wind power systems. So, the back-to-back PWM converters using actual switching power devices can be replaced by the function model which consists of the controlled-current sources and the controlled-voltage sources [19]. With this function model, the simulation executing time for the flicker analysis in DFIG wind turbine systems is significantly reduced by about $80 \%$.

\section{CONTROL SCHEME OF DFIG SYSTEMS}

\section{A. Control of back-to-back PWM converters}

The dq-axis vector control schemes are used for the GSC and the RSC of the DFIG wind turbine systems [15], [20]-[22]. The control structure of the GSC consists of the outer DC-link voltage control and reactive power control 


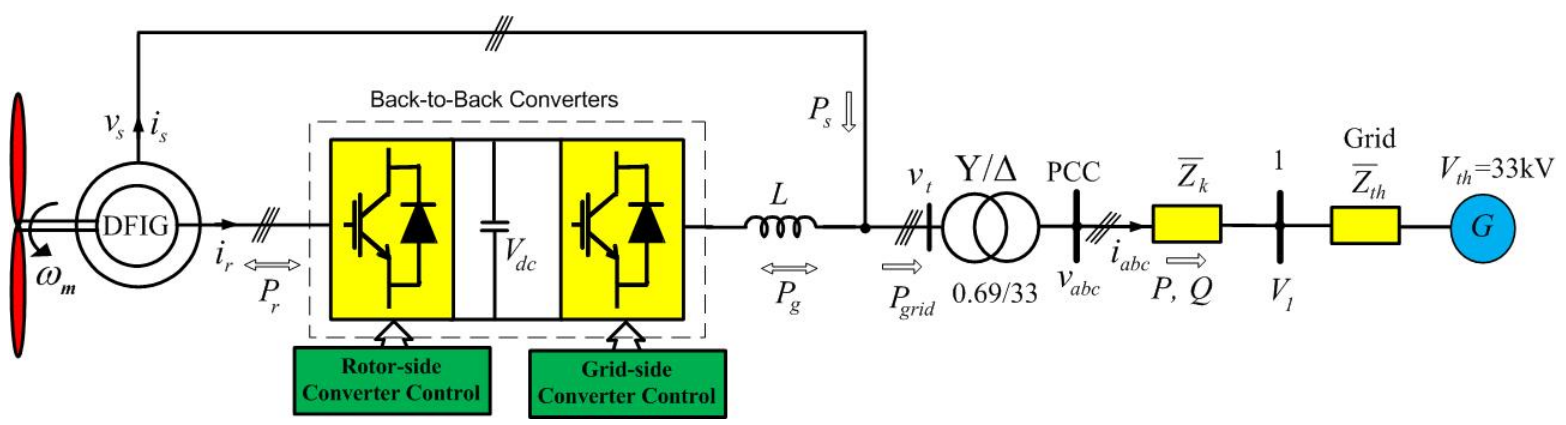

Fig. 1. Circuit configuration of grid-connected variable-speed wind turbines.

loops, and the inner current control loops. The DC-link voltage is usually controlled to be constant regardless of the direction of the rotor power. The reactive power reference is related with exciting currents of the DFIG, which may be given as zero.

For the RSC, there are the outer stator active and reactive power control loops and the inner current control loops. The stator power reference is obtained from the maximum power point tracking (MPPT) control [23]. Also, the reactive power reference is given by the upper-level controller which manages the power system operation. Normally, it is given as zero, which provides a unity power factor operation.

\section{B. Pitch angle control}

There are two operating modes in wind turbine systems according to the wind speed. Below the rated wind speed, the blade pitch angle is fixed to give the maximum output power. In this region, the characteristic curve reflects the basic law of power conversion, in which the power is proportional to the cube of the wind speed [15]. At higher wind speeds than the rated value, the blade pitch angle is controlled to protect the turbines, where the output power is limited at the rated value.

The controller of the blade pitch angle is simply a speed controller of the turbine, which is referred to in [15].

\section{REACTIVE POWER COMPENSATION}

\section{A. Strategy of compensation}

The line voltage drop is given as [8], [12]

$$
\begin{aligned}
\Delta \dot{V} & =\frac{P R_{l}+Q X_{l}}{V_{1}}+j \frac{P X_{l}-Q R_{l}}{V_{1}} \\
& =\Delta V_{l}+j \Delta \delta_{l}
\end{aligned}
$$

where $\Delta V_{l}=\left(P R_{l}+Q X_{l}\right) / V_{1}$ and $\Delta \delta_{l}=\left(P X_{l}-Q R_{l}\right) / V_{1}$, $V_{1}$ is the line voltage terminal, $P, Q, R_{l}$ and $X_{l}$ are the line active and reactive power, the resistance and the reactance of the line, respectively. It is known that the imaginary part ( $\Delta \delta_{l}$ ) is much smaller than the real part ( $\Delta V_{l}$ ) since the phase difference between the grid voltage and the PCC voltage is very small [12]. Thus, the voltage drop can be approximated as

$$
|\Delta \dot{V}| \approx \frac{P R_{l}+Q X_{l}}{V_{1}}
$$

As can be known, the voltage drop depends on the line impedance, the active and reactive power. Normally, the reactive power is controlled to be zero, so the voltage drop is dominated by the active power. Also, due to the large variation of the generator power, the voltage drop in (7) will vary and lead to the voltage variations at the PCC.

At zero voltage drop, the reactive power in the line is given from (7) by

$$
Q=-P\left(\frac{R_{l}}{X_{l}}\right)=-P \cdot K_{L}
$$

where $K_{L}=R_{l} / X_{l}$ is the reciprocal of the line impedance ratio. For a zero voltage drop, on the contrary, the reactive power can be controlled by the RSC of DFIG wind turbine system. The reference value of the reactive power ( $Q_{S}^{r e f}$ ), which is determined from (8), depends on the active power at the PCC and the line impedance ratio.

In the cases of the transmission networks, due to $X_{l}>>R_{l}$, the amount of the reactive power required for the flicker reduction is not so large when compared with the distribution network where its impedance ratio is typically about 1 [11].

\section{B. Limits of reactive power compensation}

The DFIG is a wound-type rotor induction generator whose stator and rotor are connected to the grid directly and interfaced through the back-to-back converters, respectively. Normally, the converters are rated from 25 to $30 \%$ of the turbine power rating, which corresponds to the range of rotor speed variation [15], [24]. So, the converters have the ability to control the reactive power based on the grid requirement. However, the power capacity of the DFIG wind turbine 


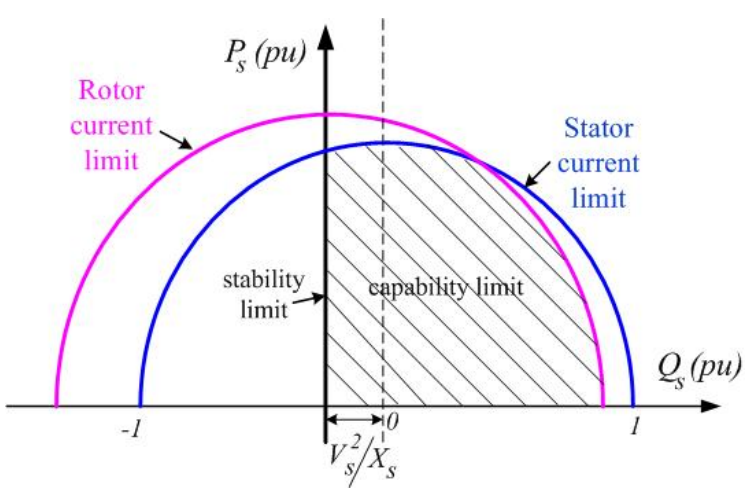

Fig. 2. Capability limit of stator reactive power required for the flicker compensation.

systems is limited by the rated current to prevent the stator and rotor from overheating.

Considering the stator current and voltage at rated value in p.u., the stator current is limited by [25]

$$
P_{s}^{2}+Q_{s}^{2}=V_{s}^{2} I_{s}^{2}
$$

where $V_{s}, I_{s}, P_{s}$, and $Q_{s}$ are the stator voltage, current, active power, and reactive power, respectively.

In general, the equation for the P-Q curves as shown in Fig. 2 is derived as [25]

$$
P_{s}^{2}+\left(Q_{s}+\frac{V_{s}^{2}}{X_{s}}\right)^{2}=\left(\frac{X_{m}}{X_{s}} V_{s} I_{r}\right)^{2}
$$

where $I_{r}$ is the rotor current, $X_{s}$ is the stator reactance, $X_{m}$ is the mutual reactance, and $\delta$ is the load angle.
From (10), the lower and upper limits of the reactive power for the RSC are given as

$$
\begin{aligned}
Q_{s \max } & =\left(\frac{X_{m}}{X_{s}} I_{r}\right) V_{s}-\frac{1}{X_{s}} V_{s}^{2} \\
Q_{s \text { min }} & =-\frac{1}{X_{s}} V_{s}^{2}
\end{aligned}
$$

It is noted from (11) and (12) that $Q_{s \text { min }}<Q_{s}^{r e f}<Q_{s \max }$. So, the capability limit of the reactive power generation from the DFIG for the flicker suppression is shown in Fig. 2.

In some technical reports, the reactive power control of DFIG wind turbines has been studied for the flicker mitigation [9], [26]. However, they have not handled the DFIG capability limits. In this work, this point is investigated in detail.

\section{ENERGY STORAGE SYSTEMS}

A control diagram of the ESS is shown in the bottom of Fig. 3. The ESS consisting of a bidirectional two-quadrant DC/DC converter and a super-capacitor bank is considered to be connected to the DC bus of the back-to-back PWM converters in the DFIG wind turbine system.

An objective of the ESS is to store or release the fluctuated power components ( $P_{\text {fluc }}^{r e f}$ ) due to the wind shear and tower shadow effects. The bidirectional DC/DC converter is operated by turning on the switches $S_{1}$ and $S_{2}$ complementarily. When the super-capacitor power $\left(P_{c}\right)$ is less than the reference value ( $P_{\text {fluc }}^{r e f}$ ), it discharges, thus operating in the boost converter mode, where $S_{1}$ is off and

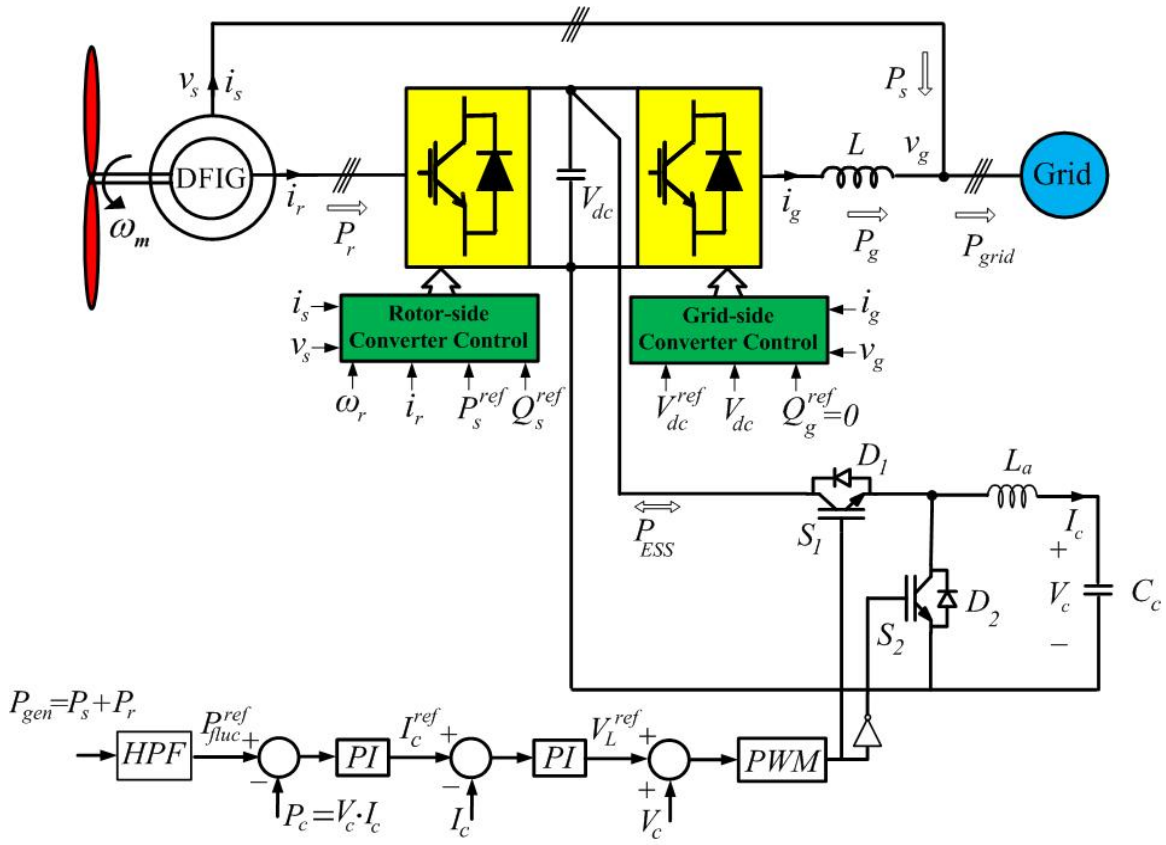

Fig. 3. Control block diagram of ECC for DFIG wind turbine system. 
$S_{2}$ is on. Reversely, the super-capacitor is charged in the buck converter mode when $S_{1}$ is on and $S_{2}$ is off.

\section{FLICKER SUPPRESSION BY REACTIVE POWER COMPENSATION AND ACTIVE POWER SMOOTHENING}

As mentioned earlier, there is a limit of the reactive power supplied by the wind turbines. Also, since the grid impedance ratio depends on the network, the reactive power is not high enough to minimize the flicker emission. So, a solution of an energy storage system which is combined together with the reactive power compensation is proposed to suppress the flicker in the system to the value of nearly zero, as expected. With this method, the flicker due to the wind speed variations is compensated by the reactive power control at the RSC. The power fluctuations caused by wind shear and tower shadow effects are suppressed by the ESS.

Fig. 3 shows the system configuration of DFIG wind turbine equipped with energy storage system and the control block diagram. The reactive power is controlled by the RSC of DFIG wind turbine systems. The control structure of the ESS is composed of the outer power control loop and the inner current control loop. As can be seen, the error between the super-capacitor power and the fluctuated power reference is processed through a PI controller, which produces the super-capacitor current reference. Then, the current controller gives the inductor voltage reference ( $V_{L}^{r e f}$ ) for the PWM.

The flicker is caused by the power fluctuations. To extract the fluctuated power components for power smoothening control, the second-order high-pass filter is applied to the generator output power $\left(P_{\text {gen }}\right)$, as shown in Fig. 3, of which transfer function is given as

$$
F(s)=\frac{s^{2}}{s^{2}+2 \xi \omega_{c} s+\omega_{c}^{2}}
$$

where $\xi$ is a damping ratio, and $\omega_{c}=2 \pi f_{c}$ is the cut-off frequency.

Normally, the wind turbine can operate in a wide speed range of 15 to $25 \mathrm{rpm}$. With this speed range, the frequency of each blade in the three-bladed wind turbine system is obtained from 0.25 to $0.42 \mathrm{~Hz}$, which has a 3p fluctuation frequency between 0.75 and $1.25 \mathrm{~Hz}$. As aforementioned, the output active power contains the fluctuation frequency components such as $3 p, 6 p$, 9p, etc, which produce the flicker.

To filter out these power fluctuations, the cut-off frequency of the high-pass filter needs to be selected at the value less than the $3 p$ fluctuation frequency $\left(f_{3 p}\right)$. So, it is
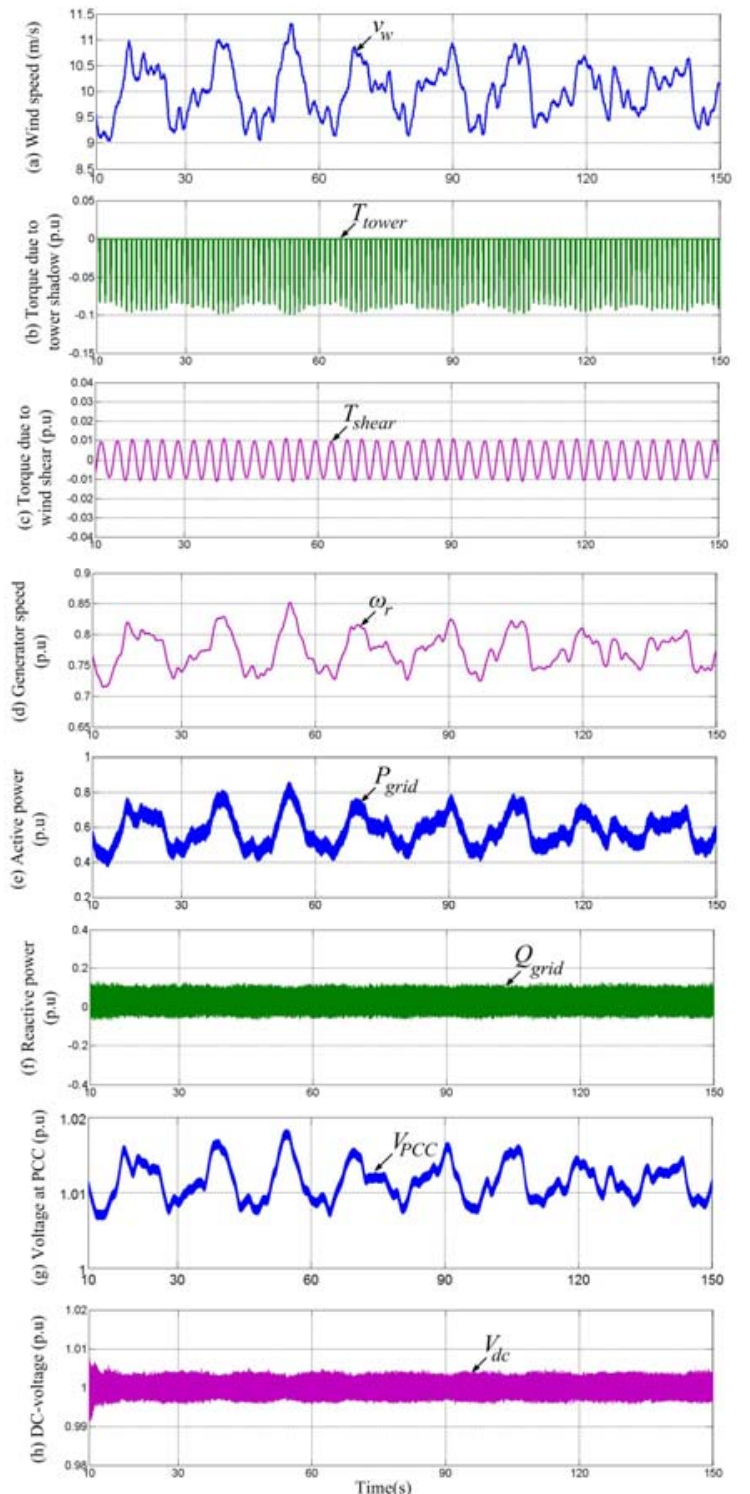

Fig. 4. Case study: conventional method.

(a) Wind speed. (b) Torque due to tower shadow. (c) Torque due to wind shear. (d) Generator speed. (e) Grid active power. (f) Grid reactive power. (g) Voltage at the PCC. (h) DC-link voltage.

selected to be $0.5 \mathrm{~Hz}$.

\section{SIMULATION RESULTS}

A 2-MW DFIG with the back-to-back PWM converters connected in the rotor circuit is driven by a wind turbine. The parameters of the wind turbine and the generator are listed in Tables I and II in the Appendix, respectively. The grid voltage is $33[\mathrm{kV}] / 60[\mathrm{~Hz}]$. The DC-link voltage is controlled at $1.2[\mathrm{kV}]$ for the IGBT back-to-back PWM converters, whose switching frequency is $2.5[\mathrm{kHz}]$. The wind shear effect is relatively low (1\%), whereas the effect of the tower shadow is a little larger, in this case, approximately $10 \%$ of 


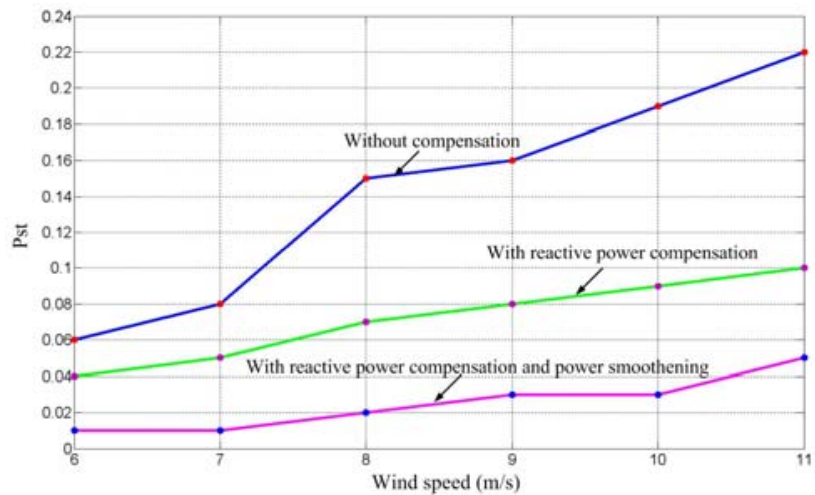

Fig. 5. $P_{s t}$ with the changes of mean wind speed for 2MW DFIG wind turbine system (simulation).

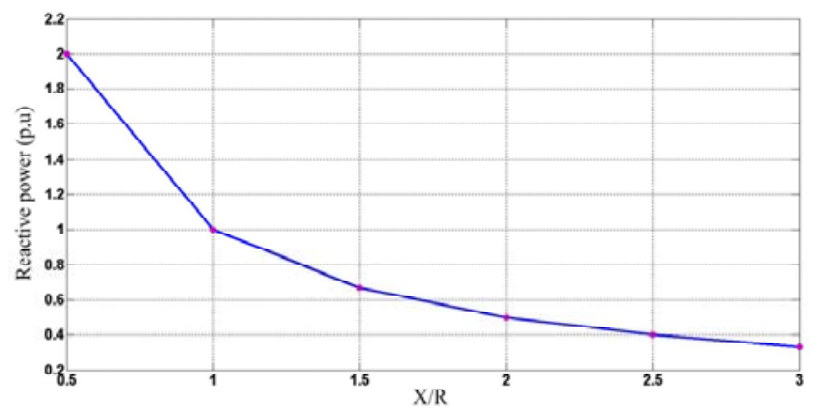

Fig. 6. Required reactive power for the flicker suppression with regard to the grid impedance ratio of $X / R$.

the total aerodynamic torque. According to the IEC standard IEC 61000-4-15 [27], a model of the flicker meter is built to calculate the short-term flicker severity $P_{s t}$ at the PCC. The simulations have been performed using PSCAD/EMTDC.

Fig. 4 shows the system performance in the conventional method without any reactive power compensation. The wind speed, torque due to tower shadow, torque due to wind shear and generator speed are illustrated in Fig. 4(a)-(d), respectively. By this, the grid active power and reactive power are much fluctuated, as shown in Fig. 4 (e) and (f), respectively. The voltage at the PCC and DC-link voltage are shown in Fig. 4(g) and (h), respectively. When the line impedance ratio is $1.962(R=0.4414[\Omega], L=2.297[\mathrm{mH}])$ the line impedance angle is about 63 degrees. The output reactive power is controlled so that the voltage difference between the PCC and the grid is zero, and then the flicker level is decreased.

As shown partially in Fig. 5, the variation of the short-term flicker severity depends on the change of the mean wind speeds for the two cases, without and with the reactive power compensation. Since the output power is low at the low wind speed, $P_{s t}$ is low in both cases. At the mean wind speed of 6 $\mathrm{m} / \mathrm{s}$, the values of $P_{s t}$ are 0.06 and 0.04 without and with the reactive power compensation, respectively. Then, the flicker goes up as the wind speed increases. For the mean wind speed of $11 \mathrm{~m} / \mathrm{s}$, the flicker values reach 0.22 and 0.1 without and with the reactive power compensation, respectively. It can be seen that $P_{s t}$ is low in the conventional method, when compared with the reactive power compensation at the same conditions. Therefore, the control scheme of the output reactive power is relatively an effective way for the flicker mitigation. However, it should be noted that the required reactive power depends on the grid conditions, when the grid impedance ratio becomes low. From (8), it is known that the grid impedance ratio determines the grid power factor which decides the desired reactive power to suppress the flicker.

Fig. 6 illustrates the variation of the required reactive power according to the grid impedance ratio. It is clearly seen that the reactive power needed for the flicker mitigation increases dramatically as the grid impedance ratio decreases. With the high wind speed and the low grid impedance ratio, the flicker cannot be mitigated only by the reactive power compensation. As shown in Fig. 6, when the ratio of $X / R$ is 0.5 , the grid impedance angle is 26.57 degrees.

So, the reactive power required for the flicker suppression is 2.0 p.u., whereas the capability of reactive power generation of the DFIG is only 0.4026 p.u. and its stability margin at the steady state is 0.371 p.u., as the generator power reaches the rated value. It is difficult for the generator to provide the amount of reactive power as required by the grid due to the power capacity limits. So, the full flicker suppression method using both the reactive power and active power control is required in addition.

With the proposed method, the reactive power control at the RSC and the active power control with an ESS using the super-capacitor are investigated at different mean wind speeds. Fig. 7 shows the system performance with the proposed method, at the mean wind speed of $10 \mathrm{~m} / \mathrm{s}$. The generator active power contains a considerable amount of fluctuations due to the wind shear and the tower shadow effects, as shown in Fig. 7(a). Then, the grid active power feeding the grid is smoothened by using the ESS, as illustrated in Fig. 7(b). Also, the stator reactive power is needed for the flicker reduction, as shown in Fig. 7(c). The voltage waveform at the PCC is shown in Fig. 7(d). The super-capacitor power, current and voltage are illustrated in Fig. 7(e)-(g), respectively. Thus, the flicker is mitigated by eliminating the fluctuations of the output active power and absorbing the reactive power from the DFIG. 

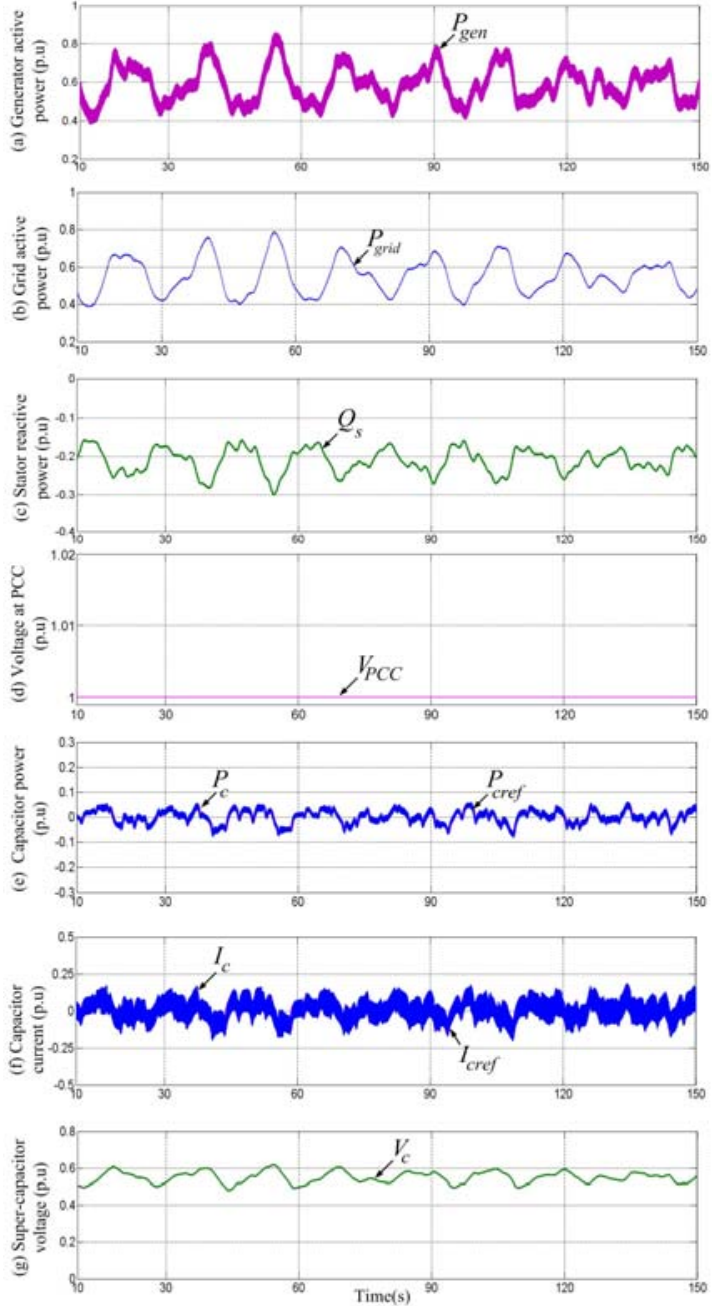

Fig. 7. With reactive power compensation and active power smoothening.

(a) Generator active power. (b) Grid power. (c) Stator reactive power. (d) Voltage at the PCC. (e) Super-capacitor power. (f) Super-capacitor current. (g) Super-capacitor voltage.

The super-capacitor is used to absorb the fluctuation components of the active power which is extracted from the wind turbines. The capacitance of the super-capacitor has to be designed in order to store sufficiently large energy. From this, the value of the super-capacitor is selected to be $1[F]$.

It can be seen from Fig. 7 (g) that the voltage of the super-capacitor is reduced by about a-half, compared with the DC-link voltage. With the proposed method, the power fluctuations are removed, so that more power can be obtained from the wind turbine and the output power is smoothened as well.

To investigate the effect of the active power ripples inducing the flicker, a frequency analysis of the generator output power is carried out for the two cases, without and
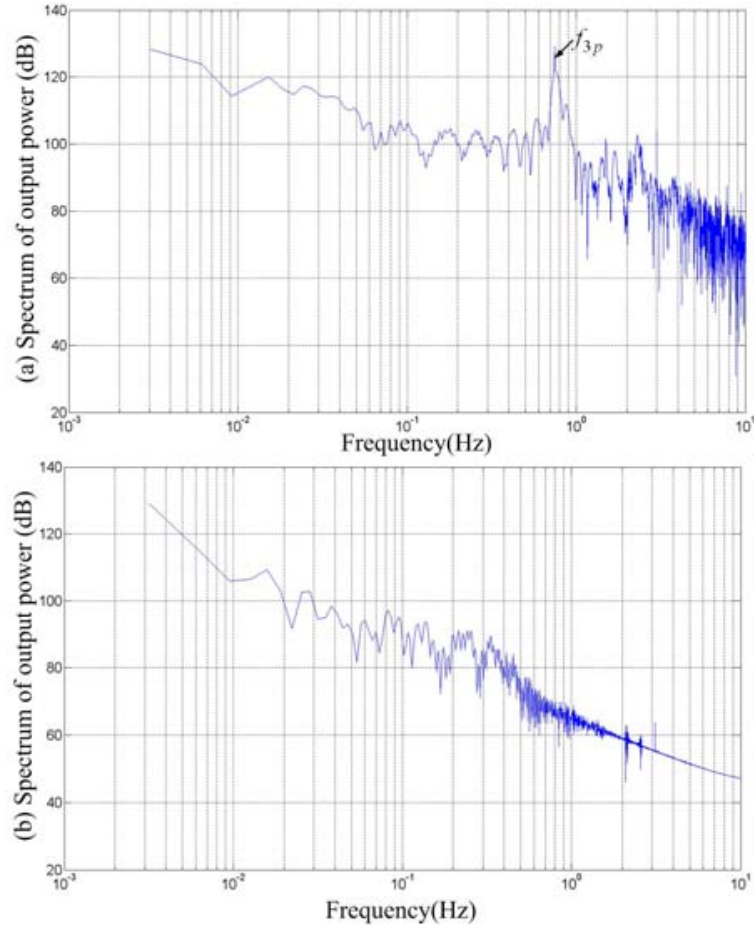

Fig. 8. Spectrum of output active power of 2MW-DFIG wind turbine (simulation).

(a) Without power smoothening control. (b) With power smoothening control.

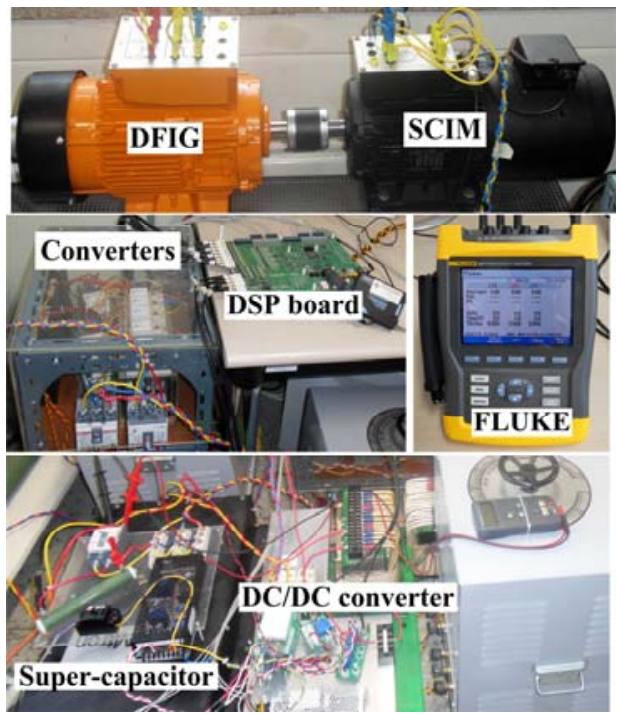

Fig. 9. Layout of the experimental set-up.

with power smoothening control using the ESS in Fig. 8. Compared with Fig. 8(a), the fluctuation components of the output power, which are one of the causes of the flicker emission in the variable-speed wind turbine systems, is obviously mitigated, as shown Fig. 8(b). 
(a)

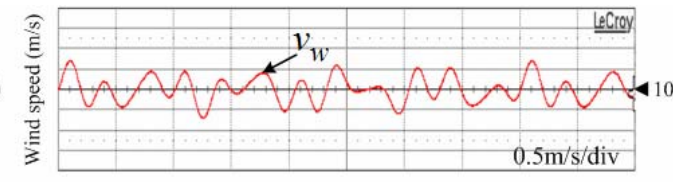

(b)

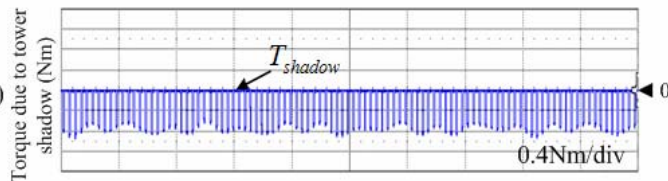

(c)
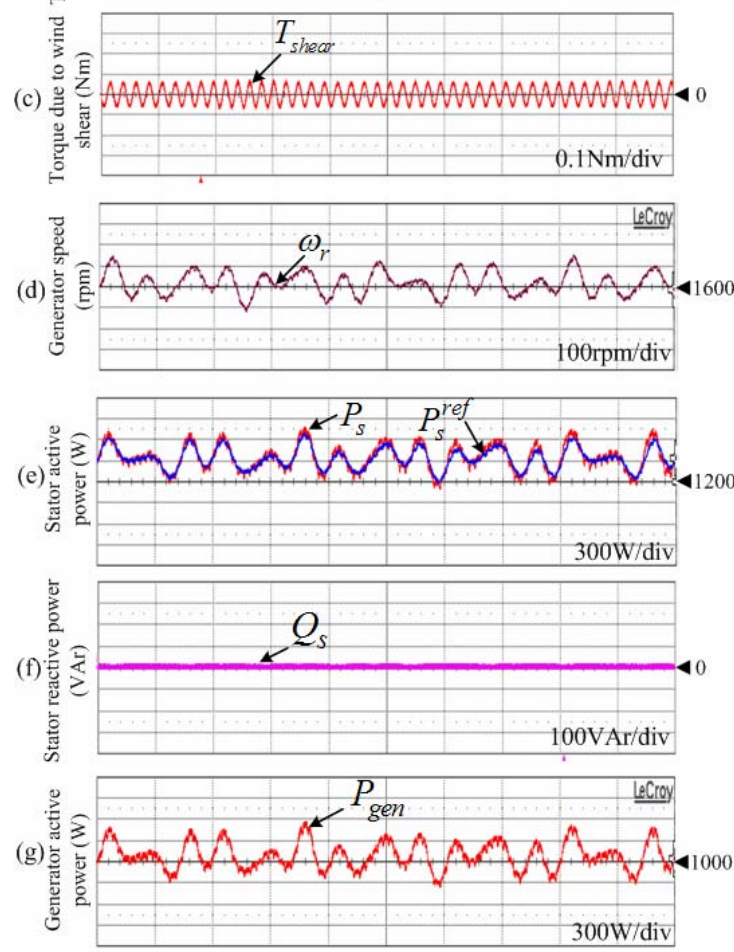

(h)

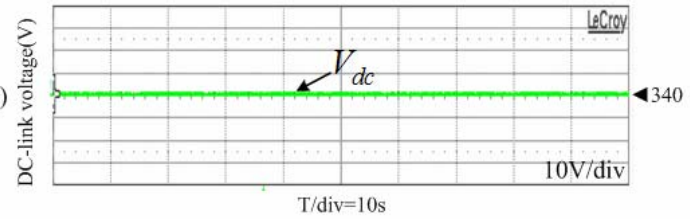

Fig. 10. Case study: conventional method.

(a) Wind speed. (b) Torque due to tower shadow. (c) Torque due to wind shear. (d) Generator speed. (e) Stator active power. (f) Stator reactive power. (g) Generator active power. (h) DC-link voltage.

As aforementioned, Fig. 5 illustrates the variations of the short-term flicker severity, $P_{s t}$, with the mean wind speed in the case of the reactive power control and the active power smoothening. In this case, the $P_{s t}$ is 0.01 at the lowest wind speed and only 0.05 at the highest wind speed. As expected, the percentages of the flicker reduction for the reactive power compensation only and for both reactive power compensation and the active power smoothening are $52.63 \%$ and $84.21 \%$, respectively, compared with the conventional method, at the mean wind speed of $10 \mathrm{~m} / \mathrm{s}$. So, the method of the reactive

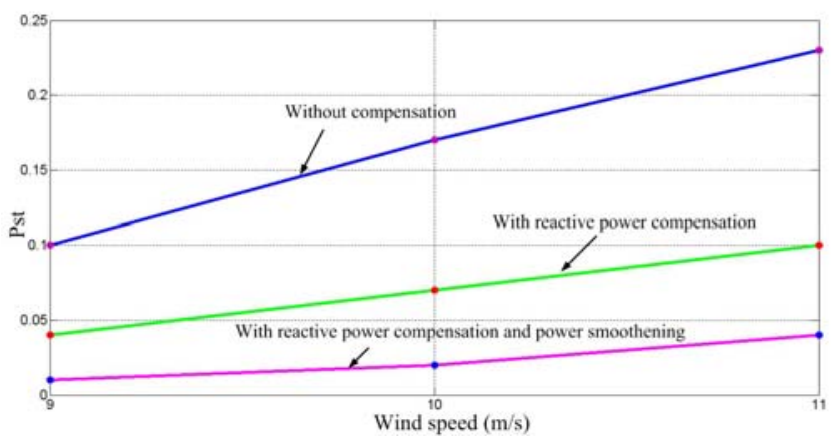

Fig. 11. $P_{s t}$ with regard to the mean wind speed for $3 \mathrm{~kW}$ DFIG wind turbine system (experiment).

power compensation combined with the active power smoothening gives a lower flicker level, when compared with the conventional one.

The flicker mitigation controller using the super-capacitor can only damp the $3 p$ active power fluctuations due to the wind shear and tower shadow effects [13]. However, the proposed method gives the better performance of the active power smoothening. So, the combination of the reactive power compensation and active power control using the ESS can reduce the flicker more significantly. Since the high grid impedance causes a significant voltage drop in the distribution network, the proposed method is very effective.

\section{EXPERIMENTAL RESULTS}

To demonstrate the validity of the proposed algorithm, the experiment has been carried out for a 3 [kW] DFIG wind turbine simulator. The layout of the experimental set-up at the laboratory is shown in Fig. 9, where a squirrel-cage induction motor is used as a turbine simulator. A flicker meter, FLUKE $434 / 435$, is used for actual measurement. The parameters of the DFIG and the ESS are listed in Table III and IV in the Appendix, respectively. The grid voltage is $220[\mathrm{~V}] / 60[\mathrm{~Hz}]$. The DC-link voltage is controlled at $340[\mathrm{~V}]$ for the IGBT back-to-back PWM converters whose switching frequency is $5[\mathrm{kHz}]$. For the line impedance ratio of 5.92 at laboratory system $(R=0.14[\Omega], L=2.2[\mathrm{mH}])$ where the line impedance angle is about 80 degrees.

Fig. 10 shows the system performance in the conventional method, without the reactive power compensation, at the mean wind speed of $10 \mathrm{~m} / \mathrm{s}$. The wind speed, torque due to tower shadow, torque due to wind shear and generator speed are illustrated in Fig. 10(a)-(d), respectively. The stator active and reactive power, and the generator active power are fluctuated, as shown in Fig. 10 (e)-(g), respectively. The 


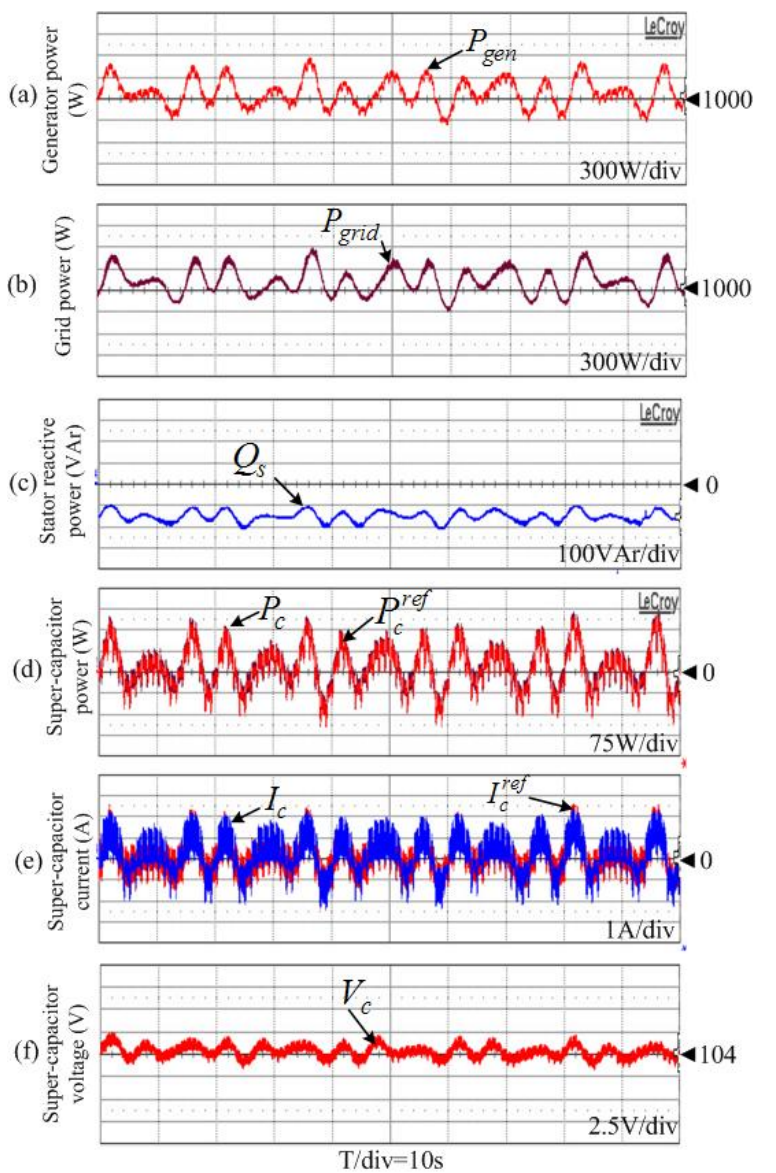

Fig. 12. With the energy storage system and reactive power compensation.

(a) Generator power. (b) Grid power. (c) Stator reactive power.

(d) Super-capacitor power. (e) Super-capacitor current. (f) Super-capacitor voltage.

\section{DC-link voltage is illustrated in Fig. 10(h).}

With the reactive power compensation, the short-term flicker severity is reduced as shown partially in Fig. 11, compared with the conventional method. At the lowest mean wind speed, the $P_{s t}$ is 0.04 and this value reaches 0.1 at the highest wind speed.

As expressed similarly in the simulation for the $2 \mathrm{MW}$ DFIG wind turbine system, Fig. 6 shows the changes of the required reactive power according to the grid impedance ratio in [pu] system (3kVA-base case), with 3kW-DFIG wind turbine system for the experiment. The flicker cannot be sufficiently suppressed only by the reactive power compensation, in the cases of the high wind speed and the low grid impedance ratio. The reactive power needed for the flicker suppression is 2.0 p.u., whereas the capability of reactive power generation of the DFIG is just 0.226 p.u. and its stability margin is 0.962 p.u. when the generator power operates at the rated condition. So, the full flicker mitigation
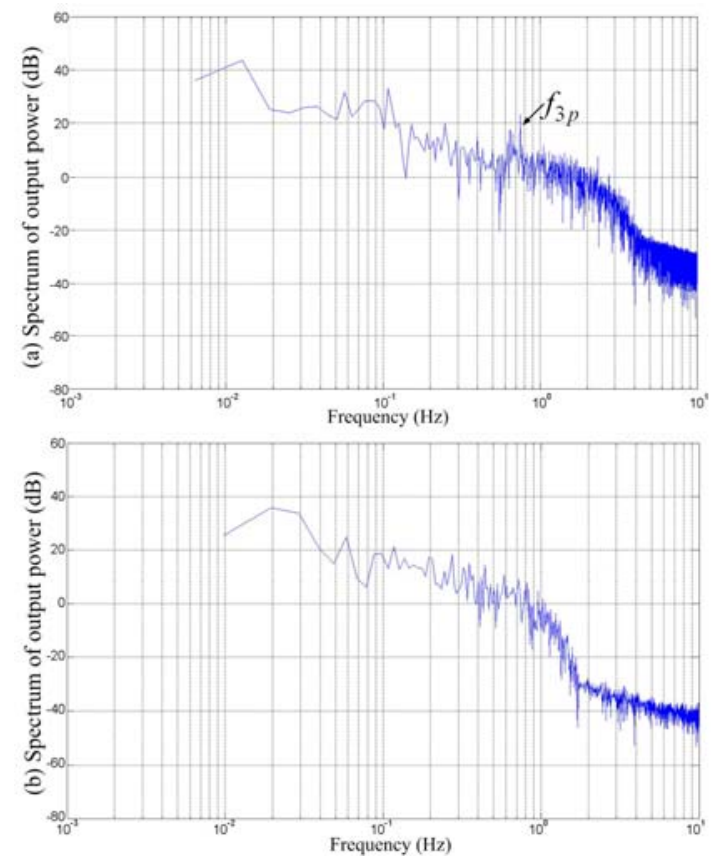

Fig. 13. Spectrum of output active power of 3kW-DFIG wind turbine (experiment).

(a) Without power smoothening control.

(b) With power smoothening control.

method applying both the reactive power and active power control is required.

Fig. 12 shows the system performance with combining the reactive power compensation and the active power smoothening. As can be seen from Fig. 12(b), the active power delivered to the grid is much more smoothened than the generator active power, as illustrated in Fig. 12(a).

The stator reactive power is required for the flicker compensation, as shown in Fig. 12(c). Since the super-capacitor is applied to absorb the extracted fluctuation components, the super-capacitor power, current and voltage are illustrated in Fig. 12(d)-(f), respectively.

Fig. 13(a) shows the frequency analysis of the generator output power fed to the grid without any reactive power compensation. By applying the ESS, the fluctuation components of the output power, which cause the flicker emission, are eliminated as illustrated in Fig. 13(b).

In some cases where the grid impedance ratio is low, the method using both the reactive power compensation and the active power smoothening gives the lower flicker value. As can be seen in Fig. 11, the $P_{s t}$ in the proposed method is dramatically decreased, compared with only the reactive power compensation. The flicker values are just 0.01 and 0.04 at the mean wind speeds of $9 \mathrm{~m} / \mathrm{s}$ and $11 \mathrm{~m} / \mathrm{s}$, respectively. 
As expected, the percentages of the flicker reduction in the case of the reactive power compensation only and in the case of both reactive power compensation and the active power smoothening are $58.82 \%$ and $88.24 \%$, respectively, when compared with the conventional method, at the mean wind speed of $10 \mathrm{~m} / \mathrm{s}$. Therefore, the method of the reactive power compensation and the active power smoothening is verified to be very effective for the flicker reduction.

Actually, the method for flicker suppression proposed in this paper can be applied to other types of variable-speed wind turbines with full-scale back-to-back PWM voltage-source converters, such as synchronous generators or induction generators, not only for DFIG. In this case, the required reactive power for flicker suppression is controlled at the grid-side converter.

\section{CONCLUSIONS}

The variable-speed wind turbine with a DFIG is capable of controlling the output active and reactive power independently. So, the reactive power can be compensated by the wind turbines using the output active power and the grid impedance ratio, so that the variations of the voltage at the PCC is decreased, which leads to the flicker reduction. However, the reactive power compensation itself is insufficient to eliminate the flicker fully in the case, where the grid impedance ratio is low. Meanwhile, the ESS with the super-capacitor can absorb the fluctuated active power from the generator, by which the output active power is smoothened. Therefore, by combining the active power smoothening and the reactive power compensation, the flicker can be much reduced.

\section{APPENDIX}

The parameters of the wind turbines, the generators and the energy storage devices used for the simulations and the experiments are listed in Table I-IV.

TABLE I

PARAMETERS OF WIND TURBINE FOR SIMULATION

\begin{tabular}{|c|c|}
\hline Rated power & $2[\mathrm{MW}]$ \\
\hline Blade radius & $39[\mathrm{~m}]$ \\
\hline Air density & $1.225\left[\mathrm{~kg} / \mathrm{m}^{3}\right]$ \\
\hline Max. power conv. coefficient & 0.4 \\
\hline Cut-in speed & $3[\mathrm{~m} / \mathrm{s}]$ \\
\hline Cut-out speed & $25[\mathrm{~m} / \mathrm{s}]$ \\
\hline Rated wind speed & $11[\mathrm{~m} / \mathrm{s}]$ \\
\hline Blade inertia & $6.3 \times 10^{6}\left[\mathrm{~kg} . \mathrm{m}^{2}\right]$ \\
\hline
\end{tabular}

TABLE II

PARAMETERS OF 2 [MW] DFIG FOR SIMULATION

\begin{tabular}{|c|c|}
\hline Rated power & $2[\mathrm{MW}]$ \\
\hline Grid voltage & $33[\mathrm{kV}]$ \\
\hline Stator voltage/frequency & $690[\mathrm{~V}] / 60[\mathrm{~Hz}]$ \\
\hline Stator resistance & $0.00488[\mathrm{p} . \mathrm{u}]$ \\
\hline Rotor resistance & $0.00549[\mathrm{p} . \mathrm{u}]$ \\
\hline Stator leakage inductance & $0.0924[\mathrm{p} . \mathrm{u}]$ \\
\hline Rotor leakage inductance & $0.0995[\mathrm{p} . \mathrm{u}]$ \\
\hline Generator inertia & $200\left[\mathrm{~kg} . \mathrm{m}^{2}\right]$ \\
\hline
\end{tabular}

TABLE III

PARAMETERS OF DFIG FOR EXPERIMENT

\begin{tabular}{|c|c|}
\hline Rated power & $3[\mathrm{~kW}]$ \\
\hline Stator voltage/frequency & $220[\mathrm{~V}] / 60[\mathrm{~Hz}]$ \\
\hline Stator resistance & $0.0372[\mathrm{p} . \mathrm{u}]$ \\
\hline Rotor resistance & $0.04419[\mathrm{p} . \mathrm{u}]$ \\
\hline Stator leakage inductance & $0.07737[\mathrm{p} . \mathrm{u}]$ \\
\hline Rotor leakage inductance & $1.5592[\mathrm{p} . \mathrm{u}]$ \\
\hline Generator inertia & $0.0033\left[\mathrm{~kg} . \mathrm{m}^{2}\right]$ \\
\hline
\end{tabular}

TABLE IV

PARAMETERS OF ESS FOR EXPERIMENT

\begin{tabular}{|c|c|}
\hline Inductor $\left(L_{f}\right)$ & $2.5[\mathrm{mH}]$ \\
\hline Super-capacitor & $2.92[\mathrm{~F}]$ \\
\hline DC operating voltage & $120[\mathrm{~V}]$ \\
\hline Switching frequency & $5[\mathrm{kHz}]$ \\
\hline
\end{tabular}

\section{ACKNOWLEDGMENT}

This research has been supported by the Basic Science Research Program through the National Research Foundation of Korea (NRF) funded by the Ministry of Education, Science and Technology (2009-0077374).

\section{REFERENCES}

[1] Z. Lubosny, "Wind turbine operation in electric power system,” Springer-Verlag, 2003.

[2] J. Schlabbach, D. Blume, and T. Stephanblome, "Voltage quality in electrical power systems," The Institution of Electrical Engineers, London, United Kingdom, 2001.

[3] A. Larsson, "Flicker emission of wind turbines during continuous operation,” IEEE Trans. Energy Convers., Vol. 17, No. 1, pp. 114-118, Mar. 2002.

[4] C. V. Moreno, H. A. Duarte, and J. U. Garcia, "Propagation of flicker in electric power networks due to wind energy conversions systems," IEEE Trans. Energy Convers., Vol. 17, No. 1, pp. 267-272, Jun. 2002.

[5] G. Gerdes and F. Santjer, "Power quality of wind turbines and their interaction with the grid," in Proc. Eur. Wind Energy Conf., 14-16, Thessaloniki, Greece, pp. 1152-1157, Oct. 1998.

[6] M. P. Papadopoulos, S. A. Papathanassiou, S. T. Tentzerakis, and N. G.Boulaxis, "Investigation of the flicker emission by grid connected wind turbines," in Proc. 
of 8th Int. Conf. Harmonics Quality of Power, 14-16, 2, Athens, Greece, pp. 1152-1157, Oct. 1998.

[7] T. Sun, Z. Chen, and F. Blaabjerg, "Flicker study on variable speed wind turbines with doubly fed induction generators,” IEEE Trans. Energy Convers., Vol. 20, No. 4 , pp. 896-905, Dec. 2005.

[8] T. L. Van, T. H. Nguyen, and D.-C. Lee, "Flicker mitigation in DFIG wind turbine systems," in Proc. European Conf. Power Electronics and Applications (EPE), Birmingham, U.K, pp. 1-10, Aug/Sept. 2011.

[9] Y. S. Kim and D. J. Won, "Mitigation of the flicker level of a DFIG using power factor angle control," IEEE Trans. Power Del., Vol. 24, No. 2, pp. 2457-2458, Oct. 2009.

[10] T. Sun, Z. Chen, and F. Blaabjerg, "Flicker mitigation of grid connected wind turbines using STATCOM," in Proc. Int. Conf. Power Electron., Mach. Drive, The Institution of Electrical Engineers, pp.175-180, Mar. 2004.

[11] M. Triggianese, J. Morren, D. Haan, and P. Marino, "Improved and extended DG capability in voltage regulation by reactive and active power," in Proc. Int. Conf. Power Eng., Energy Electr. Drives, Setubal, Portugal, pp. 583-588, Apr. 2007.

[12] N. C. Scott, D. J. Atkinson, and J. E. Morrell, "Use of load control to regulate voltage on distribution networks with embedded generation,” IEEE Trans. Power Syst., Vol. 17, No. 2, pp. 510-515, Mar. 2002.

[13] W. Hu, Z. Chen, Y. Wang, and Z. Wang, "Flicker mitigation by active power control of variable speed wind turbines with full-scale back-to-back power converters," IEEE Trans. Energy Convers., Vol. 24, No. 3, pp. 640-649, Sept. 2009.

[14] C. Nichita, D. Luca, B. Dakyo, and E. Ceanga, "Large band simulation of the wind speed for real time wind turbine simulators," IEEE Trans. Energy Convers. Vol. 17, No. 4, pp. 523-529, Dec. 2002.

[15] V. Akhmatov, "Analysis of dynamic behavior of electric power systems with large amount of wind power," Ph.D. dissertation, Technical University of Denmark, Kgs. Lyngby, Denmark, Apr. 2003.

[16] A. O. Ibrahim, T. H. Nguyen, D.-C. Lee, and S.-C. Kim, "A fault ride-through technique of DFIG wind turbine systems using dynamic voltage restorers," IEEE Trans. Energy Convers. Vol. 26, No. 3, pp. 871-882, Sept. 2011.

[17] M. Chinchilla, S. Arnaltes, and J. L. Rodriguez-Amenedo, "Laboratory set-up for wind turbine emulation," IEEE ICIT Conf. Proc., 8-10, 1, pp. 553-557, Dec. 2004.

[18] PSCAD-EMTDC version 4.2, The professional's Tool for Electromagnetic Transients Simulation, Manitoba HVDC Research Center Inc., 2007.

[19] T. L. Van and D.-C. Lee, "Developing function models of back-to-back PWM converters for simplified simulation," Journal of Power Electronics, Vol. 11, No. 1, pp. 51-58, Jan. 2011.

[20] R. Pena, J. C. Clare, and G. M. Asher, "Doubly fed induction generator using back-to-back PWM converters and its application to variable-speed wind-energy generation,” IEE Proc. Electron. Power Appl., Vol. 143, No. 3, pp. 231-241, May 1996.

[21] G. Byeon, I. K. Park, and G. Jang, "Modeling and control of a doubly-fed induction generator (DFIG) wind power generation system for real-time simulations," Journal of Electrical Engineering and Technology, Vol. 5, No. 1, pp. 61-69, Jan. 2010.

[22] S. Z. Chen, N. C. Cheung, K.C. Wong, and J. Wu, "Integral variable structure direct torque control of doubly fed induction generator,” IET Renew. Power. Gener., Vol. 5 , No. 3, pp. 18-25, 2011.
[23] R. Datta and V. T. Ranganathan, “A method of tracking the peak power points for a variable speed wind energy conversion system," IEEE Trans. Energy Convers., Vol. 25, No.2, pp. 356-368, Mar. 2003.

[24] S. Engelhardt, I. Erlich, C. Feltes, J. Kretschmann, and F. Shewarega, "Reactive power capability of wind turbines based on doubly fed induction generators," IEEE Trans. Energy Convers. Vol. 26, No. 1, pp. 364-372, Mar. 2011.

[25] D. S. Martin, S. Arnaltes, and J. L. R. Amenedo, "Reactive power capability of doubly fed asynchronous generators," Electr. Power Syst. Res., 78, pp. 1837-1840, 2008.

[26] L. Meegahapola, B. Fox, and D. And Flynn, "Flicker mitigation strategy for DFIGs during variable wind conditions," Proc. IEEE PES, pp. 1-8, 2010.

[27] IEC STD. 61000-4-15: "Electromagnetic Compatibility (EMC)-Part 4: Testing and Measurement Techniques-Section 15: Flickermeter-Functional and Design Specifications,” Nov. 1997.

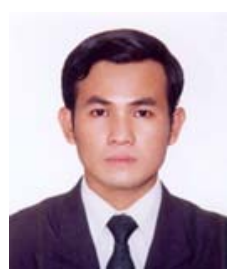

Tan Luong Van was born in Vietnam, in 1979. He received the B.Sc and M.Sc degree in electrical engineering from University of Technology, Ho Chi Minh city, Vietnam, in 2003 and 2005, respectively. He is currently working torward the Ph.D degree in Yeungnam University, Korea. He was a lecturer in Ho Chi Minh city Electric Power College, Viet Nam in 2003. His research interests include power converters, machine drives, wind power generation, power quality and power system.

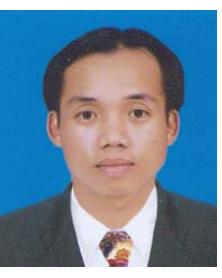

Thanh Hai Nguyen was born in Dong Thap, Viet Nam in 1980. He received the B.Sc. Eng. degree from Technology University of Ho Chi Minh city, in 2003 and M.Sc degree at Department of Electrical Engineering, Yeungnam University, Korea in 2010 where, he is currently working toward the Ph.D degree. He was an assistant lecturer in College of Technology, Can Tho university, Viet Nam in 2003. His research interests are power converters, machine drives, and wind power generation.

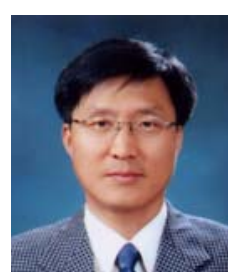

Dong-Choon Lee received the B.S., M.S., and Ph.D. degrees in Electrical Engineering from Seoul National University, Seoul, Korea, in 1985, 1987, and 1993, respectively. He was a Research Engineer with Daewoo Heavy Industry from 1987 to 1988. Since 1994, he has been a faculty member of the Dept. of Electrical Engineering, Yeungnam University, Gyeongbuk, Korea. Currently, he is serving as a Publication Editor, Journal of Power Electronics, Korea. As a Visiting Scholar, he joined Power Quality Laboratory, Texas A\&M University, College Station in 1998, and Electrical Drive Center, University of Nottingham, U.K. in 2001, and Wisconsin Electric Machines \& Power Electronic Consortium, University of Wisconsin, Madison in 2004. His research interests include ac machine drives, control of power converters, wind power generation, and power quality. 